\title{
The polyamine spermine in retarding salinity-induced stress in canola
}

\author{
Salwa A. Orabi, Tarek A. El-Shahawy and Faida A. Sharara \\ Botany Department, National Research Centre, El Buhouth St., Postal Code 12622, Dokki, Cairo, \\ Egypt
}

Received: 05 Jan. 2020 / Accepted 02 Mar. 2020 / Publication date: 15 Mar. 2020

\begin{abstract}
Salinity is one of the most heightened threats to global agriculture and sustainable development, which is expected to exacerbate by climate change. The current study aims at assessing the effect of a number of salinity concentrations ( $250 \mathrm{ppm}$ as tap water, 3000 and $6000 \mathrm{ppm}$ ) under the use of spermine $(0,50$ and $100 \mathrm{ppm})$ on canola plant, including the oxidative adaptations, growth and yield productivity. A greenhouse experiment was conducted in this context during winter season of (2015/16) in a randomized complete block design with nine treatments and three replicates. The use of spermine alone promoted greater vegetative growth and efficient crop production. Under salinity treatment plants appeared stressed, resulting in decadent vegetative growth and poor productivity in particular at the high concentration. Exogenous application of spermine compensated for the low vegetative growth of salt stressed plants, and resulted in more robust plants for seed formation by adjusting the homeostatic equilibrium at cellular and molecular levels. The reversal of inhibitory effect of salinity stress was conferred by triggering the activity of enzymatic [i.e., glutathione reductase (GR), ascorbate peroxidise (APX), phenylalanine ammonia lyase (PAL)] and non-enzymatic [i.e., glutathione (GSH) and ascorbate (AsA), total phenols] antioxidant systems as well as reducing oxidants of the detrimental reactive oxygen species (ROS). The greatest values were obtained under the use of spermine at $100 \mathrm{ppm}$ concentration with a conspicuous impact in reducing electrolytes leaked from affected tissues. It follows from this that spermine is significant in neutralizing salinity-induced harmful impacts, and that using it at the proper rate can be quite beneficial in the exploitation of saltwater to irrigate important crops such as canola.
\end{abstract}

Keywords: abiotic stress, antioxidants, canola, salinity, ROS, spermine.

\section{Introduction}

In the absence of armed conflicts, the $21^{\text {st }}$ began with agriculture as a top priority to meet the world's growing food needs. As expected, the coming ages will witness the emergence of many entities as a potential agricultural superpower. But the conflict between nature and man ultimately dominates the situation. With the world undergoing dramatic changes in the congenital conditions for agriculture and livestock production, radical changes in agricultural practices, adaptations and mitigation strategies will be required to keep pace with these changes. These challenges are not individually technical, but are inextricably linked with the contemporary environmental changes. Currently, future trajectories of average crop yields, cropland expansion and food security are managed by future climate changes in the principal agricultural regions of the world. The inconsistent relationship between population density and land available for cultivation poses another pressing question about our agricultural future and food security (Josephson et al., 2014).

Global scarcity of water resources, climate changes, environmental pollution and increased salinization of soil and water are the most important challenges that we face today, and are widely assumed to have not only natural but anthropogenic reasons. For the last 100 years, the global mean temperature has increased to actually more than $15^{\circ} \mathrm{C}$, which places a great deal of pressure on the current vegetation, and negatively affect the productivity of the main crops. This grade is likely to increase by another $2-3^{\circ} \mathrm{C}$, mainly caused by a higher use of fossil fuels and an intensified conventional agricultural practices throwing a greater burden on existing agricultural production (Karmakar et al., 2016). For all economic crops, average yields are only a fraction somewhere between $20 \%$ and $50 \%$ of standard yields, with no evidence for yields having exceeded this threshold to date (Lobell et al., 2009). A key obstacle in this regard appears to be uncertainty in growing season weather, in particular with

Corresponding Author: Tarek A. El-Shahawy, Botany Department, National Research Centre, El Buhouth St., Postal Code 12622, Dokki, Cairo, Egypt. E-mail: el_shahawy4@yahoo.com 
increasing drought and soil salinity, which will worsen in many territories because of global climate change.

Salinity is one of the most devastating abiotic environmental stresses that affects plant growth and impairs agricultural production of most cultivated crops. This problem becomes more severe in arid and semi-arid regions, where annual rainfall is low and evapo-transpiration is high. Land vulnerable to salinization is increasing on a daily basis. It has been estimated that $20 \%$ of the total cultivated and $33 \%$ of irrigated lands are affected by high salinity worldwide, with an expected increase to $50 \%$ of the total arable land by the year 2050 (Jamil et al., 2011). Various reasons underlie increased salinized areas around the world (about 10\% annually) including high surface evaporation due global climate change and global warming, low precipitation, irrigation with saline water and poor farming practices (Scheumann and Freisem, 2002).

There are different mechanisms by which salinity stress can occur affecting yield and produce more or less distinct deficiency symptoms. The effect of salinity begins from germination to physiological maturity and depends on multiple factors, including the amount, intensity, duration of salinization and plant growth stage (Gupta and Hung, 2014). Once the capacity of the cell to assimilate salts is exhausted, salts build up outside vacuole, either in the cytoplasm or in the intercellular spaces outside the cell leading to cell dehydration and death (Volkmar et al., 1998). Many functional disorders have been described with signs and symptoms that vary, to some extent, between plant species. Chlorosis on the tips of mature older leaves, developing into necrosis, then death of leaves are among the distinctive features (Acosta-Motos et al., 2017). Lose of or decreasing activity of enzymes and disturbing cell metabolism due to ion toxicities; limited uptake of nutrients and minerals due to agricultural depletion of soil nutrients are all common across most crops (Negrão et al., 2017). A fundamental effect is to inhibit plant access to soil's water as a result of increasing the osmotic pressure of the soil solution (Sheldon et al., 2004). The plant content of photosynthetic pigments and carbohydrate production was also found to be severely affected by salinity (Abdallah et al., 2016). Moreover, increased uptake of toxic ions services to induce ROS generation inside cell, which act as secondary damaging factors to various physiological processes and plant anatomy (Aslam et al., 2017).

In their efforts to cope with the adverse conditions, plants have evolved an efficient enzymatic and non-enzymatic antioxidative system to secure themselves against the oxidative damage and fine modulation of low levels of ROS. Plants with high levels of enzymatic antioxidants [i.e., peroxidase (POD), superoxide dismutase (SOD), catalase (CAT), GR, APX, PAL] and none-enzymatic antioxidants (e.g., GSH and AsA), either constitutive or induced, have been reported to have greater resistance to the oxidative damage caused by the environmental stresses (He and Gao, 2008).

There are accumulating reports that polyamines are involved in abiotic stress response, even though the role of such organic compounds is not fully elucidated. Studies using a spermine-deficient mutant referred to the protective role of spermine against high salt and drought stresses (Cheng et al., 2004). Empirical research studies reveal that spermine is effective in a three-step manner. Firstly, spermine blocks the $\mathrm{Na}^{+}$leakage from monovalent cation-permeable FV (fast-activating vacuole) channels including slow-activating vacuolar (SV) channels (Dobrovinskaya et al., 1999), and this is done through a few or hundred $\mu \mathrm{M}$ (Kusano et al., 2007). Secondly, spermine may control $\mathrm{Ca}^{2+}$ allocation in the cytosol through regulating $\mathrm{Ca}^{2+}$-permeable channels including CAXs vascular channels (Cheng et al., 2005). Lastly, change of $\mathrm{Ca}^{2+}$ compartmentation induced by spermine is a strong evidence to prevent $\mathrm{Na}^{+}$entry through HKT1-type channels in the plasma membrane and enhance SOS1 activity, a plasma membrane $\mathrm{Na}^{+} / \mathrm{H}^{+}$antiporter (Zhu, 2001).

In the current study, we assess whether spermine plays a role in mitigating the high salt stress using canola as one of the crops that has recently gained much attention in the Egyptian agricultural community. A sudden increase in the area occupied by this plant is expected in the foreseeable future. Canola has a high potential for oil production with a range of uses. In recent times, there has been largescale spread of the plant in the Mediterranean region where the demand for vegetable oils for industrial use has increased dramatically.

\section{Materials and Methods}

\section{Plant sowing and treatments}

A pot experiment was conducted during the winter season of $(2015 / 2016)$ at the wire house of the National Research Centre, Dokki, Cairo, Egypt. Canola seeds (Brassica napus L., cv. pactol) were 
purchased from Agricultural Research Centre, Ministry of Agriculture, Egypt. After surface sterilization using $1 \%(\mathrm{v} / \mathrm{v})$ sodium hypochlorite $(5 \%)$ for 2 minutes, the seeds were washed thoroughly ( 3 times) with distilled water and allowed to dry on filter paper $\left(1 \mathrm{~h} / 25^{\circ} \mathrm{c}\right)$ for $15 \mathrm{~min}$. The seeds were subjected to treatment by soaking for $12 \mathrm{hrs}$ in spermine solution at 50 and $100 \mathrm{ppm}$ concentrations. Control treatment used seeds pre-soaked for a similar time in distilled water. The seeds were sown $(3 \mathrm{~cm}$ depth) in circular pottery pots $(30 \mathrm{~cm}$ diameter across top, $10 \mathrm{~cm}$ diameter across base and $35 \mathrm{~cm}$ vertical height) on November $15^{\text {th }}, 2015$. The soil texture was clay soil (Table 1). To avoid compression, the soil was mixed with sand $(3: 1 \mathrm{v} / \mathrm{v})$ for improving drainage performance.

Pots were chemically fertilized using calcium superphosphate $\left(15.5 \% \mathrm{P}_{2} \mathrm{O}_{5}\right)$ at a rate of $10 \mathrm{~g} / \mathrm{pot}$ before sowing and addition of nitrogen fertilizer as ammonium sulphate $(20.5 \% \mathrm{~N})$ at $2 \mathrm{~g} /$ pot twice $(4$ and 6 weeks after planting). The experiment composed of nine treatments with three replicates each in a completely randomized block design. As plants reach three-leaf stage (20 days old), thinning was done to the most three healthy, uniform seedlings in each pot. The plants in each pot were regularly watered to field capacity with freshwater until salinity treatments were imposed.

The plants were subjected to salinity stress 35 days after sowing using 250 "as tape water", 3000 and $6000 \mathrm{ppm}$ concentrations. To create salt stress of the prescribed levels, seawater was mixed with freshwater, and the plants were continually irrigated with an equal volume at $7-10$ day intervals, or as needed required. Otherwise, all plants received the ordinary agricultural practices needed to continue growth. The empirical values of water electrical conductivity (EC), $\mathrm{pH}$, anions and cations in both irrigation water and soil used in the experiment are as shown in Table (1).

Table 1: Key features of irrigation water and soil implicated in the study

\begin{tabular}{|c|c|c|c|c|c|c|c|c|c|c|}
\hline \multirow{2}{*}{ Element } & \multirow{2}{*}{$\begin{array}{c}\mathbf{E c}^{*} \\
\mathbf{d S m}^{-1}\end{array}$} & \multirow[b]{2}{*}{ pH } & \multicolumn{4}{|c|}{ Cations meq $\mathrm{L}^{-1}$} & \multicolumn{4}{|c|}{ Anions meq $\mathrm{L}^{-1}$} \\
\hline & & & $\mathrm{Ca}^{+2}$ & $\mathrm{Mg}^{+2}$ & $\mathrm{Na}^{+}$ & $\mathbf{K}^{+}$ & $\mathrm{HCO}_{3}^{-}$ & $\mathrm{CO}_{3}^{-2}$ & $\mathrm{SO}_{4}^{-2}$ & $\mathrm{Cl}^{-}$ \\
\hline Water & & & & & & & & & & \\
\hline Tap water & 0.22 & 7.45 & 0.95 & 0.25 & 2.54 & 0.25 & 0.12 & 0.00 & 1.35 & 2.98 \\
\hline Seawater & 49.80 & 7.78 & 44.80 & 14.90 & 445.55 & 72.80 & 6.28 & 0.00 & 75.29 & 446.00 \\
\hline Soil & & & & & & & & & & \\
\hline Clay & 1.52 & & 5.34 & 1.98 & 6.11 & 0.40 & 1.37 & 0.00 & 7.23 & 5.78 \\
\hline Sandy & 0.16 & & 2.72 & 2.38 & 1.35 & 0.23 & 1.12 & 0.00 & 4.25 & 0.78 \\
\hline
\end{tabular}

*EC $\left(\mathrm{dSm}^{-1}\right)$, electric conductivity (deciSiemens per meter); meq $\mathrm{L}^{-1}$, milliequivalents of solute per litre

\section{Data recorded}

\section{Vegetative growth and yield attributes}

Growth measurements (e.g., stem length, $\mathrm{cm}$; root length, $\mathrm{cm}$; shoot and root dry weights, g) were taken 40 days after starting salinity stress treatment. At the maturity stage of the life cycle (155 days from planting), plants were harvested to determine the number of pods per plant, number of seeds per pod and 100-seed weight trait (g).

\section{Antioxidant enzymes activity}

Leaf samples were harvested 40 days after salinity stress treatment from each group to measure the associated physiological changes in APX, GR and PAL enzyme activities. Extraction procedure relied on homogenising $5 \mathrm{~g}$ of frozen leaves from each treatment in pre-chilled mortar containing 10 $\mathrm{mL}$ of potassium sulphate puffer $(50 \mathrm{mM} ; \mathrm{pH} 7)$ with $1 \%$ polyvinyle pyrolidone (PVP) and $0.1 \mathrm{Mm}$ EDTA. After repeating extraction twice, the supernatants were bulked and raised to a certain volume. To ensure success, all steps were carried out under freezing conditions with maintaining final solutions under $-4^{\circ} \mathrm{C}$.

The activity of the enzymes was assayed differently based on their types. The APX-specific activity (EC 1.11.1.11) was determined according to the methodology of Nakano and Asda (1981). One APX activity unit is defined as the amount of enzyme that breaks down or oxidizing $1 \mu$ mole of AsA per min and determined as ( $\mu \mathrm{mol} / \mathrm{g} \mathrm{Fr}$. Wt.). Glutathione reductase activity was assayed according to Zanetti (1979). Enzyme activity (unit= nmol/g Fr. Wt.) is defined as the amount of GR enzyme (EC 1.6.4.2) that decreases $A_{340}$ per min. In this case, the enzyme ability to reduce oxidized glutathione (GSSG) is determined indirectly by the measurement of the consumption of NADPH, as demonstrated 
by a decrease in absorbance at $340 \mathrm{~nm}$ (A340) as a function of time. The activity of PAL ( $\mu \mathrm{mol} / \mathrm{g} \mathrm{Fr}$. Wt.) was assayed following the method adopted by He et al. (2001). The activity of PAL is defined as the amount of enzyme forming $1 \mu \mathrm{mol}$ of transcinnamic acid from the substrate phenylalanine per min.

\section{Non-enzymatic antioxidants}

The non-enzymatic antioxidants such as GSH, AsA and total phenols were determined in the seeds (mg/g Dr. Wt.) of canola plants using various assay techniques. Ascorbic acid content was measured following the procedure of Kampfenkel et al. (1995). Reduced glutathione was estimated using Ellman's reagent according to Silber et al. (1992). Tissues composition of total phenols was measured as described by Zhang and Wang (2001).

\section{Reactive oxygen species}

Determination of the generated ROS due to salinity treatments including hydrogen peroxide $\left(\mathrm{H}_{2} \mathrm{O}_{2} ; \mu \mathrm{mol} / \mathrm{g}\right.$ Fr. Wt. $)$ and superoxide $\left(\mathrm{O}_{2}{ }^{-} ; \mathrm{A} 680 / \mathrm{g}\right.$ Fr. Wt. $)$ was conducted following the methods of Jana and Choudhuri (1981) and Doke (1983), respectively. Measuring $\mathrm{H}_{2} \mathrm{O}_{2}$ relied basically on the reduction of nitro blue tetrazolium (NBT).

\section{Electrolyte leakage}

Determination of injury as electrolyte leakage from plant tissue was carried out following the methodology of Gilley and Fletcher (1997). In this regard, leaf discs of canola plants (75 days old) were thoroughly washed (3 times) with deionised water to remove potential surface-adhered electrolytes. Ten uniform sized canola leaf discs $(0.5 \mathrm{~cm}$ diameter) were placed in closed tubes containing $5 \mathrm{~mL}$ of deionised water and incubated at room temperature $\left(23-28{ }^{\circ} \mathrm{C}\right)$ for $24 \mathrm{~h}$. Afterwards, the initial electrical conductivity of the solution (EC1) was determined using a conductometer YSI (Yellow Springs Instrument Co., Inc., ohio, U.S.A.) Model 32 Conductance Meter. The samples were then incubated in a water bath at $95{ }^{\circ} \mathrm{C}$ for $20 \mathrm{~min}$ to release all electrolytes, cooled down to $25^{\circ} \mathrm{C}$ and their final electrical conductivity (EC2) was estimated. The electrolyte leakage (EL) was calculated from $\mathrm{EL}=(\mathrm{EC} 1 / \mathrm{EC} 2) \times 100(\%)$.

\section{Statistical analysis}

Statistical analysis data of all traits were collected, processed and analyzed. Tests of significance were performed using analysis-of-variance (ANOVA) table and L.S.D. test at 5\% probability to compare means according to Gomez and Gomez (1984).

\section{Results}

The plant growth and development presented by canola plants in response to salinity and combined application with spermine are illustrated in Table (2). Without spermine, salinity treatments severely hampered the growth of canola plants which peaked at $6000 \mathrm{ppm}$ concentration (Table 2). Initially, the plant appeared salt stressed and a delay in the growth of leaves was observed before developing chlorosis that covered oldest leaves quickly. This developed to necrosis affecting progressively younger tissues and led to shed oldest leaves as a common response, particularly at the higher salinity level (6000 ppm). Foliage that had not developed chlorosis was characterized by short, stiff leaves and thin, low branching stems. Salinity stress appeared sever on root growth (shorter roots and lower weight) compared to the shoot growth (stem length and dry weight). A $13.66-23.02 \%$ reduction occurred over root growth and $6.64-14.04 \%$ on stem growth at both levels of salinity stress compared to the normal control.

On the other hand, positive results were obtained at the level of improving the vegetative growth of canola plants due to the treatment by spermine either alone or under salinity additions (Table 2). Under the sole application of spermine, remarkable results were recorded on increasing the organic matter content within treated plants in both root $(21.59 \%)$ and shoot $(32.38 \%)$ tissues, notably at the higher concentration of spermine treatment compared to stem $(8.49 \%)$ and root (14.65\%) elongation. The combined application between the two elements of study did show the functional role of spermine in eliminating salinity-induced effects. The highest significant values in canola growth were for the highest concentration of spermine, regardless of salinity level used. 
Table 2: The interaction between spermine and salinity-induced effects on growth vigor of canola plants 40 days after the beginning of salinity treatment

\begin{tabular}{|c|c|c|c|c|c|}
\hline \multicolumn{2}{|c|}{ Treatment (ppm) } & \multicolumn{4}{|c|}{ Growth traits/plant } \\
\hline Salinity & Spermine & $\begin{array}{l}\text { Stem length } \\
(\mathrm{cm})\end{array}$ & $\begin{array}{l}\text { Root length } \\
\text { (cm) }\end{array}$ & $\begin{array}{l}\text { Shoot dry } \\
\text { weight (g) }\end{array}$ & $\begin{array}{l}\text { Root dry } \\
\text { weight (g) }\end{array}$ \\
\hline \multirow{6}{*}{$\begin{array}{c}\text { Tap water } \\
\quad(250)\end{array}$} & \multirow[b]{2}{*}{${ }^{\dagger} 0$} & 55.33 & 19.50 & 7.70 & 2.55 \\
\hline & & ${ }^{*} 100$ & 100 & 100 & 100 \\
\hline & \multirow{2}{*}{50} & 58.00 & 21.00 & 8.60 & 2.90 \\
\hline & & 104.83 & 107.78 & 112.35 & 114.90 \\
\hline & \multirow{2}{*}{100} & 60.00 & 22.33 & 9.31 & 3.35 \\
\hline & & 108.49 & 114.65 & 121.59 & 132.38 \\
\hline \multirow{6}{*}{3000} & \multirow{2}{*}{0} & 51.67 & 17.00 & 6.82 & 2.05 \\
\hline & & 93.36 & 86.34 & 88.67 & 80.95 \\
\hline & \multirow{2}{*}{50} & 53.00 & 18.00 & 7.26 & 2.30 \\
\hline & & 95.83 & 92.44 & 94.56 & 91.22 \\
\hline & \multirow{2}{*}{100} & 54.33 & 18.67 & 7.67 & 2.45 \\
\hline & & 98.21 & 95.86 & 99.89 & 96.72 \\
\hline \multirow{6}{*}{6000} & \multirow{2}{*}{0} & 47.00 & 15.00 & 6.12 & 1.80 \\
\hline & & 84.96 & 76.98 & 79.97 & 71.06 \\
\hline & \multirow{2}{*}{50} & 49.00 & 16.33 & 6.41 & 1.97 \\
\hline & & 88.58 & 83.80 & 83.48 & 77.96 \\
\hline & \multirow[b]{2}{*}{100} & 52.00 & 17.33 & 6.65 & 2.20 \\
\hline & & 94.00 & 88.85 & 86.67 & 86.77 \\
\hline \multirow{2}{*}{ LSD $_{0.05}$} & & 2.11 & 1.42 & 0.76 & 0.26 \\
\hline & & 3.82 & 7.45 & 10.45 & 11.18 \\
\hline
\end{tabular}

${ }^{\dagger}$ Considered as a control. "Values expressed as a percentage of control "all lower measurements".

(LSD) values calculated from the statistical analysis of the data were for both means and data as a percentage of control

The effect on yield components had a similar trend as on vegetative growth (Table 3). Salinity stress resulted in great reductions in the number of pods per plant and number of seeds per pod (between $14.42-38.48 \%$ ), but far less on the 100 -seed weight (up to $21.67 \%$ reduction) as compared with the control. The most significant reduction was recorded with the transfer to the highest salinity concentration (6000 ppm).

Table 3: Crop-yield components of canola as affected by the different treatments of spermine and salinity stress levels

\begin{tabular}{|c|c|c|c|c|}
\hline \multicolumn{2}{|c|}{ Treatment (ppm) } & \multicolumn{3}{|c|}{ Yield traits/plant } \\
\hline Salinity & Spermine & $\begin{array}{c}\text { No. of } \\
\text { pods/plant }\end{array}$ & $\begin{array}{c}\text { No. of } \\
\text { seeds/pod }\end{array}$ & $\begin{array}{c}\text { 100-seed weight } \\
\text { (g) }\end{array}$ \\
\hline \multirow{6}{*}{$\begin{array}{c}\text { Tap water } \\
\text { (250) }\end{array}$} & \multirow{2}{*}{${ }^{\dagger} 0$} & 60.00 & 10.33 & 0.21 \\
\hline & & ${ }^{*} 100$ & 100 & 100 \\
\hline & \multirow{2}{*}{50} & 64.00 & 11.67 & 0.24 \\
\hline & & 107.28 & 113.33 & 121.67 \\
\hline & \multirow{2}{*}{100} & 71.00 & 13.33 & 0.25 \\
\hline & & 118.44 & 129.39 & 123.33 \\
\hline \multirow{6}{*}{3000} & \multirow{2}{*}{0} & 51.33 & 7.67 & 0.19 \\
\hline & & 85.58 & 74.55 & 93.33 \\
\hline & \multirow[b]{2}{*}{50} & 55.00 & 8.66 & 0.19 \\
\hline & & 91.70 & 84.24 & 93.33 \\
\hline & \multirow{2}{*}{100} & 57.00 & 10.00 & 0.20 \\
\hline & & 95.13 & 96.97 & 100 \\
\hline \multirow{6}{*}{6000} & \multirow{2}{*}{0} & 45.00 & 6.33 & 0.16 \\
\hline & & 75.02 & 61.52 & 78.33 \\
\hline & \multirow{2}{*}{50} & 48.00 & 7.67 & 0.18 \\
\hline & & 80.02 & 74.55 & 90.00 \\
\hline & \multirow{2}{*}{100} & 53.00 & 8.33 & 0.19 \\
\hline & & 88.38 & 80.91 & 93.33 \\
\hline \multirow{2}{*}{$\operatorname{LSD}_{0.05}$} & & 2.11 & 1.00 & 0.01 \\
\hline & & 3.78 & 9.65 & 6.34 \\
\hline
\end{tabular}

${ }^{*}$ Same footnote as contained in Table 2. 
Without salt addition, spermine caused the yield component to increase to the maximum, in particular at the high concentration. Under $100 \mathrm{ppm}$ spermine concentration, the number of pods per plant was increased by $18.44 \%$ and their content of seeds by $29.39 \%$ with a marked increase on the 100 -seed weight trait (33.33\%) in comparison with the control. Under salinity stress, spermine led, to a large extent, to mitigate the salinity-induced modulation of yield parameters, in particular with the plants grown under the mixture pattern (3000 ppm salinity stress plus $100 \mathrm{ppm}$ spermine concentration). In this context, a $100 \%$ increase in spermine concentration (from 50 to $100 \mathrm{ppm}$ ) made yield components of those plants grown under $3000 \mathrm{ppm}$ salinity stress as close as those grown under normal conditions. Despite being less efficient under the high concentration of salinity (6000 ppm), increased concentration of spermine largely compensated for the harmful impact of salinity on yield components.

As a fundamental part of the study, the data in Tables (4) and (5) show the impact of the different treatments on the endogenous enzymatic and non-enzymatic antioxidants (Table 4) including the production of oxygen-based radicals; ROS (Table 5). Reactive oxygen species formation and induction of enzymatic (APX, GR, PAL) and non-enzymatic (AsA, GSH, total phenols) antioxidants were increased in plant tissues of those grown under salinity stress. A pronounced effect was observed in reducing the formation of highly toxic $\mathrm{O}_{2}^{-}$and $\mathrm{H}_{2} \mathrm{O}_{2}$ oxidants under the use of spermine as a result of increasing enzymatic and non enzymatic antioxidant components. A variation in plant response, however, was evident based on the treatment used.

Table 4: Enzymatic and non-enzymatic antioxidant responses of canola leaves under different salinity/spermine applications

\begin{tabular}{|c|c|c|c|c|c|c|c|}
\hline \multicolumn{2}{|c|}{$\begin{array}{l}\text { Treatments } \\
(\mathrm{ppm})\end{array}$} & \multicolumn{3}{|c|}{$\begin{array}{c}\text { (i) Enzymatic antioxidant } \\
\text { Activities (in leaves) } \\
\end{array}$} & \multicolumn{3}{|c|}{$\begin{array}{c}\text { Non-enzymatic antioxidant } \\
\text { content (in seeds) }\end{array}$} \\
\hline \multirow[t]{2}{*}{ Salinity } & \multirow[t]{2}{*}{ Spermine } & APX & GR & PAL & AsA & GSH & $\begin{array}{c}\text { Total } \\
\text { phenols }\end{array}$ \\
\hline & & \multicolumn{3}{|c|}{ (Unit/min/g Fr. Wt.) } & \multicolumn{3}{|c|}{ (mg/g Dr. Wt.) } \\
\hline \multirow{6}{*}{$\begin{array}{c}\text { Tap water } \\
\text { (250) }\end{array}$} & \multirow{2}{*}{$\dagger 0$} & 0.461 & 367.77 & 24.26 & 16.25 & 22.21 & 30.62 \\
\hline & & ${ }^{*} 100$ & 100 & 100 & 100 & 100 & 100 \\
\hline & \multirow{2}{*}{50} & 0.491 & 381.83 & 26.15 & 17.64 & 24.78 & 31.15 \\
\hline & & 106.53 & 103.83 & 107.82 & 108.55 & 111.57 & 101.74 \\
\hline & \multirow{2}{*}{100} & 0.520 & 392.99 & 27.38 & 19.86 & 26.15 & 31.40 \\
\hline & & 112.96 & 106.88 & 112.95 & 122.26 & 117.74 & 102.58 \\
\hline \multirow{6}{*}{3000} & \multirow{2}{*}{0} & 0.595 & 401.92 & 26.13 & 14.86 & 20.73 & 31.70 \\
\hline & & 129.30 & 109.36 & 107.66 & 91.54 & 93.34 & 103.53 \\
\hline & \multirow{2}{*}{50} & 0.833 & 489.01 & 28.58 & 16.12 & 23.38 & 32.63 \\
\hline & & 180.88 & 132.98 & 117.89 & 99.20 & 105.30 & 106.59 \\
\hline & \multirow{2}{*}{100} & 1.086 & 569.39 & 31.11 & 18.20 & 24.03 & 33.57 \\
\hline & & 236.05 & 155.00 & 128.35 & 112.03 & 108.23 & 109.71 \\
\hline \multirow{6}{*}{6000} & \multirow{2}{*}{0} & 0.684 & 468.91 & 28.38 & 13.24 & 17.17 & 32.13 \\
\hline & & 148.30 & 127.71 & 117.13 & 81.47 & 77.35 & 104.93 \\
\hline & \multirow{2}{*}{50} & 0.882 & 522.50 & 32.35 & 14.86 & 21.67 & 34.04 \\
\hline & & 191.50 & 142.36 & 133.45 & 91.42 & 97.55 & 111.18 \\
\hline & \multirow{2}{*}{100} & 0.908 & 529.20 & 32.83 & 17.90 & 23.88 & 34.83 \\
\hline & & 197.10 & 144.12 & 135.45 & 110.03 & 107.56 & 113.76 \\
\hline \multirow{2}{*}{ LSD $_{0.05}$} & & 0.050 & 30.45 & 1.61 & 1.15 & 0.91 & 1.41 \\
\hline & & 12.21 & 8.99 & 6.97 & 2.98 & 4.08 & 4.63 \\
\hline
\end{tabular}

* Same footnote as contained in Table 2. ${ }^{(i)}$ APX enzyme activity as: $\mu \mathrm{mol} / \mathrm{g}$ Fr. Wt.; GR enzyme activity as: nmol/g Fr. Wt.; PAL enzyme activity as: $\mu \mathrm{mol} / \mathrm{g}$ Fr. Wt.

With the use of spermine alone, the increase in enzyme activities was not as much as (namely less) that with the addition of saline water alone or in combination with spermine. Comparatively, the best results obtained were for applying the high rate of spermine under saline conditions (Table 4). An increase range from $28.35 \%$ to $136.05 \%$ was recorded on the enzymatic antioxidant system of plants grown under salinity plus spermine at $3000 \mathrm{ppm}$ and $100 \mathrm{ppm}$ resp., compared to $35.47-97.10 \%$ for the use of spermine at the same level but under the high saline level $(6000 \mathrm{ppm})$.

Applying spermine alone slightly reduced (at an insignificant rate) ROS production $\left(\mathrm{H}_{2} \mathrm{O}_{2}\right.$ and $\mathrm{O}_{2}$ ) that may have occurred for other natural reasons (e.g., changes in climatic conditions or infection 
by pests during the growing season) rather than exposing to salinity conditions. Under salinity stress, the use of $3000 \mathrm{ppm}$ dosage has caused $\mathrm{H}_{2} \mathrm{O}_{2}$ and $\mathrm{O}_{2}$ - production to increase by $52.97 \%$ and $411.29 \%$, resp. Greater estimates were attained $(85.12 \%$ and $479 \%)$ with the applying of $6000 \mathrm{ppm}$ salinity concentration in comparison with the control. The implication of spermine alleviated ROS induction under both medium and high levels of salinity stress. The transition from the concentration of $50 \mathrm{ppm}$ to $100 \mathrm{ppm}$ achieved significant results in this regard with a unique impact under the spermine level of $100 \mathrm{ppm}$, regardless of the salinity level that had been applied (Table 5).

Table 5: Interaction of spermine on reactive oxygen species generation and electrolyte leakage induced by exogenously applied salinity in canola leaves

\begin{tabular}{|c|c|c|c|c|}
\hline \multicolumn{2}{|c|}{$\begin{array}{c}\text { Treatments } \\
\text { (ppm) }\end{array}$} & \multicolumn{2}{|c|}{ Reactive oxygen species } & \multirow{2}{*}{$\begin{array}{c}\text { Electrolyte } \\
\text { leakage } \\
(\%)\end{array}$} \\
\hline Salinity & Spermine & $\begin{array}{c}\mathbf{H}_{2} \mathbf{O}_{2} \\
(\mu \mathrm{mol} / \mathrm{g} \\
\text { Fr. Wt. })\end{array}$ & $\begin{array}{c}\mathbf{O}_{2}^{-} \\
(\mathrm{A} 680 / \mathrm{g} \\
\text { Fr. Wt.) }\end{array}$ & \\
\hline \multirow{3}{*}{$\begin{array}{c}\text { Tap water } \\
(250)\end{array}$} & $\dagger 0$ & $\begin{array}{l}6.11 \\
{ }^{*} 100\end{array}$ & $\begin{array}{c}0.27 \\
100\end{array}$ & $\begin{array}{c}48.52 \\
100\end{array}$ \\
\hline & 50 & $\begin{array}{c}6.03 \\
98.81\end{array}$ & $\begin{array}{c}0.26 \\
94.86\end{array}$ & $\begin{array}{l}45.29 \\
93.34\end{array}$ \\
\hline & 100 & $\begin{array}{c}5.83 \\
95.72\end{array}$ & $\begin{array}{c}0.25 \\
91.56\end{array}$ & $\begin{array}{l}43.86 \\
90.39\end{array}$ \\
\hline \multirow{3}{*}{3000} & 0 & $\begin{array}{c}9.32 \\
152.97\end{array}$ & $\begin{array}{c}1.38 \\
511.29\end{array}$ & $\begin{array}{c}58.07 \\
119.74\end{array}$ \\
\hline & 50 & $\begin{array}{c}8.10 \\
132.83\end{array}$ & $\begin{array}{c}1.11 \\
411.21\end{array}$ & $\begin{array}{c}56.88 \\
117.29\end{array}$ \\
\hline & 100 & $\begin{array}{c}6.77 \\
111.03 \\
\end{array}$ & $\begin{array}{c}0.91 \\
337.08 \\
\end{array}$ & $\begin{array}{c}50.76 \\
104.64 \\
\end{array}$ \\
\hline \multirow{3}{*}{6000} & 0 & $\begin{array}{c}11.29 \\
185.12\end{array}$ & $\begin{array}{c}1.56 \\
579.08\end{array}$ & $\begin{array}{c}65.48 \\
134.99\end{array}$ \\
\hline & 50 & $\begin{array}{c}9.14 \\
150.06\end{array}$ & $\begin{array}{c}1.40 \\
519.37\end{array}$ & $\begin{array}{c}61.44 \\
126.66\end{array}$ \\
\hline & 100 & $\begin{array}{c}8.35 \\
137.05\end{array}$ & $\begin{array}{c}1.13 \\
418.62\end{array}$ & $\begin{array}{c}56.80 \\
117.07\end{array}$ \\
\hline LSD $_{0.05}$ & & $\begin{array}{l}0.45 \\
8.80 \\
\end{array}$ & $\begin{array}{c}0.10 \\
25.92\end{array}$ & $\begin{array}{l}3.94 \\
8.29 \\
\end{array}$ \\
\hline
\end{tabular}

* Same footnote as contained in Table 2.

Seed composition of the reduced form of glutathione (GSH) and AsA components as nonenzymatic antioxidants were positively affected by the different treatments (Table 4). The sole application by spermine was relatively distinctive in enhancing these parameters compared to the other treatments and control. The increase was the highest at the $100 \mathrm{ppm}$ concentration. Meanwhile, there were low-level representations of GSH and AsA in plants treated with saline solution alone, which was more prejudicial at $6000 \mathrm{ppm}$ salinity stress. Such observed effect was improved with the application of spermine. The high response was achieved with the use of spermine at $100 \mathrm{ppm}$ with no significant results were observed under both salinity levels.

There were no significant representation of spermine in improving plant content of phenolic compounds when applied individually. In converse to applying saline water alone, spermine significantly promoted phenolics production in the seeds of those stressed plants achieving the highest values at the $100 \mathrm{ppm}$ concentration. In general, unique results were obtained under the salinity level of $6000 \mathrm{ppm}$, irrespective of the rate of spermine that has been used (Table 4).

An electrolyte leakage assessment of plant tissue was performed in response to various treatments (Table 5). Electrolyte leakage varied directly according to the salinity level with an obvious reformative action of spermine in counteracting threat of salt-induced effects. The results indicated that leakage of electrolytes from canola leaf discs increased with increasing salinity level from $19.74 \%$ with applying $3000 \mathrm{ppm}$ salinity concentration to $34.99 \%$ with $6000 \mathrm{ppm}$ salinity stress compared to the control. With spermine application, the amount of electrolytes leaked had subjected to a gradual decline proportionally to the concentration used. A greater impact was recorded with the use of spermine at 100 
ppm level in comparison with the lowest concentration $(50 \mathrm{ppm})$ and irrespective of the salinity level used. A part from the positive role of spermine in attenuating the harmful effect located on salt-stressed plants, the use of spermine alone has reduced much of electrolytes $(6.66-9.61 \%)$ that could normally leak for any other reason than salinization. Again, the highest rate of spermine yielded the best values in this regard (Table 5).

\section{Discussion}

Our results demonstrate the broad salinity impact on the growth and development of canola plants and could further the understanding of the interlinked impact on yield and its components. It has been noted that shoot growth was indirectly less affected by salinity stress than root growth. Damage to the root tissues, in particular at the high salt stress, to the extent that they become unable to transfer more of the toxic ions may interpret the low impact on shoot growth.

The impacts of salinity have been discussed thoroughly by many researchers, which are in apparent agreement with our results. Salinity is generally known to have substantial impacts on growth, cellular structures, and key physiological functions within different plant species (Krasensky and Jonak 2012; Negrão et al., 2017). Recent increasing evidences have implicated stress and defense response signaling in the production of secondary metabolites that are produced by plants to serve a variety of cellular functions essential for physiological processes (Isah, 2019). Numerous studies have reported evidence of a negative transition for plant growth upon salt stress imposition (Isayenkov andMaathuis, 2019). In general, salts of harmful amount in the soil water have a dual effect on plant development: (i) an osmotic pressure, which reduces the ability of plants to take up water (Aroca et al., 2012); (ii) accumulation of excess ions (i.e., $\mathrm{Na}^{+}$) inside plant causes physiological/metabolic disturbance in processes where low $\mathrm{Na}^{+}$and high $\mathrm{K}^{+}$or $\mathrm{Ca}^{2+}$ are required for optimum function (Marschner, 1995). However, toxicity of the ions may exceed the impact of osmotic pressure (Sheldon et al., 2004). Consequences of salt stress include metabolism alteration such as affecting nitrate reductase activity (Reda and Klobus, 2011), retarding enzymatic and non-enzymatic antioxidants (Abd El-Baky et al., 2003), and damaging the photosynthetic machinery, primarily photosystem II (PSII) leading to photoinhibition and loss of plant performance (Kelley and Izawa, 1978; Zaghdoudi et al., 2011). Salinity in soil or irrigation water is the main cause of chlorophyll breakdown (Abdul Qados, 2011) and imposes nutrient ( $\mathrm{P}, \mathrm{N}, \mathrm{Ca}, \mathrm{K}, \mathrm{Fe}, \mathrm{Zn}$ ) deficiency (Patel et al., 2010).

The existing results showed a significant difference upon the treatment by spermine and highlighted a strong relationship between the observed compensatory response and the concentration applied from the spermine. Spermine tagged with healthy vegetative and root growth. Taken together, our results showed that the ability of spermine to maintain stem/root growth and biomass under salinity stress improves with increasing spermine concentration. These results are consistent with what previous studies have suggested. Polyamines-induced alleviation of salt toxicity during plant growth has been studied widely on a variety of crop species (Bueno and Cordovilla, 2019). The retardation in root length or shoot length and toxic accumulation of $\mathrm{Na}^{+}$and $\mathrm{H}_{2} \mathrm{O}_{2}$ was appreciably reduced by co-treatment with spermidine or spermine (Roychoudhury et al., 2011). The previous authors commented that inhibiting the extent of salt-induced protein carbonylation, promoting protease activity, the prevention of chlorophyll degradation and enhancing sugar level may give a clear portrait of the mechanism by which the plant can overcome salt stress with the aid of polyamines. In general, polyamines confer salt tolerance by preventing growth inhibition or various forms of cellular damages, maintaining proper $\mathrm{K}^{+} / \mathrm{Na}^{+}$balance, reducing sodium uptake, improving nutrient homeostasis or triggering the level of osmolytes and activity of detoxification systems including antioxidant enzymes (Saleethong et al., 2011; Fariduddin et al., 2013).

In this study, we provide evidence of the harmful impact of salinity on canola productivity and the positive role of spermine in ameliorating such effects. In the absence of salt tolerance measure (spermine application), salinity largely damaged yield components. The poor vegetative and root growth is liable for intensifying this impact. Published studies have shown yield performance of canola as influenced by salinity stress. A longer period for grain filling in association with lowering pod number and grain number per plant was reported (Boem et al., 1994; Rezaeil et al., 2017). Multiple experiments have been conducted with parallel results on various crops. For major field and vegetable crops, a rate more than $3000 \mathrm{ppm}$ were found to have an adverse impact on yield and its components (Katerji et al., 1996). 
The effect of enhanced spermine for raising productivity among field crops is well-documented (Gupta, 2019). As a key ingredient, the increase in yield components by spermine was, in part, due to enhancing the contributions of improved vegetative growth. The good vegetative growth means more vibrant plants with larger pods, greater number of heavy seeds and subsequently a higher yield production (Ambika et al., 2014). Polyamines are generally known to improve yield and yield-related parameters in field crops via alleviating (a)biotic stresses and improving the productive processes (Saleethong et al., 2013; Chen et al., 2018). Field-supported cases of wheat, rice and soybeans provided essential evidence in understanding the mechanism by which higher polyamines relieve the damages from salinity stress (Walia et al., 2005; Amooaghaie and Moghym, 2011). Among polyamines, spermine and spermidine are better involved in the regulation of grain filling and weight of grains; a case study on wheat (Liu et al., 2013). The authors suggested that polyamines actively function in the balance of hormones that regulates the grain filling; a positive evaluation was recorded on endogenous spermine, spermidine, gibberellins, indole-3-acetic acid (IAA), zeatin+ zeatin riboside ( $Z+Z R$ ), abscisic acid (ASA), yet a significant decrease in ethylene (ETH) value was evident during estimates (Orabi and Sadak, 2015). There is evidence of an interaction relationship of exogenously applied polyamines in elevating the endogenous polyamine pools, and manipulation of cellular hormone levels, which in turn reflecting in promoting crop productivity (Liu et al., 2015b).

A major influence that had been given special attention in this study is related to the biochemical changes in the enzymatic and non-enzymatic antioxidant systems and the production of oxygen-based radicals (ROS). The data revealed a significant positive relationship of the spermine in enhancing the antioxidant defense systems and reducing the retardant ROS, which allows maintaining higher growth and yield even upon extreme stress conditions. These results confirm the findings of previous research proving the multifaceted role of polyamines in stress amelioration (Hasanuzzaman et al., 2019). Obviously, damage linked to free radicals are arising from an imbalance between radical-generating and radical-scavenging systems (Sharma et al., 2012). According to the published literature, controlling and scavenging the ROS "in chloroplast" is very essential to ensure the continual survival under various stresses (Das and Roychoudhury, 2014). For this purpose, plants have developed efficient antioxidant machinery having two arms in which enzymatic antioxidant system is the main mechanism driving persistence among plants (Xie et al., 2019).

Consistent with the general perception that spermine differentially refines plant defense responses, our results provide evidence that spermine enhance production of enzymatic antioxidants and improves salt stress tolerance of canola. The results conform to the previous research findings. The role of major polyamines in mediating salt stress and activating antioxidant enzymes during stress condition or ROS inhibition has been investigated through many studies (Saha et al., 2015; Paul et al., 2018). A great deal of research has demonstrated that polyamines function in stress tolerance largely by modulating the homeostasis of ROS due to their direct, or indirect, impacts in regulating antioxidant systems or suppressing ROS emission (Yang et al., 2007; Liu et al., 2015a). Increased focus on the link between major polyamines metabolism and defense response during plant-stress interactions have yielded a special role of spermine in eliciting an efficient defense response to biotic and abiotic stresses (Seifi and Shelp, 2019). According to the proposed model by the authors, spermine refines defense mechanisms to tailor an optimal resistance response in accordance to the nature of the biotic or abiotic stress, and this is typically associated with higher activities of SOD, CAT, GR and glutathione Stransferase (GST) besides greater production of non-enzymatic antioxidants such as AsA and GSH culminating in reduced ROS accumulation (Nahar et al., 2016). In a distinct way, spermine positively serves to promote appropriate hormone-mediated signalling pathways during environmental stresses (Alcázar et al., 2010), along with inducing several defense-related genes (Takahashi et al., 2003), thus the notion that spermine functions as a potent plant defense activator becomes more plausible (Seifi et al., 2019).

According to the current results, salinity induced an oxidative stress along with a marked increase in the non-enzymatic antioxidants, including the amounts of GSH, AsA and total phenols. Interestingly, spermine-induced modulation of non-enzymatic antioxidants resulted in a better protection against the oxidative damages of salinity in canola, which is not, however, associated with elevated ROS levels. These results showed a high degree of conformity with previous studies (Hasanuzzaman et al., 2019). The association of enzymatic and non-enzymatic antioxidant defense markers has been collectively discussed together with the protective role in counteracting the negative impacts caused by the 
environmental changes (Kiran, 2019). Biochemical and molecular features of the non-enzymatic antioxidants in which particular attention is paid to the low molecular mass compounds such as AsA, GSH, flavonoids, phenolic acids, carotenoids and tocopherols have received greater concern because of their substantial role in scavenging ROS in the different cell compartments and in response to stress conditions (Racchi, 2013). A number of studies have demonstrated that plant responds to salt-induced oxidative stress by increasing both enzymatic and non-enzymatic antioxidant mechanisms proportionally to the extent of the stress imposed (Arbona et al., 2003). Aside from being effective in increasing the activities of enzymatic antioxidants, polyamines of which spermine is a key compound enhance plant antioxidant response via improving non-enzymatic system which collectively act to inhibit the formation of ROS (Todorova et al., 2013).

Phenolic compounds are a key component in antioxidant response elements which showed greater production under the use of spermine. Recently phenolics have received considerable attention as bioactive components in plants, especially their role as antioxidant agents. There is sufficient evidence of induction of phenolic metabolism in plants as a response to multiple stresses, including soil salinity, drought and extreme temperatures (Rezazadeh et al., 2012; Rezayian et al., 2018). Nevertheless, the current understanding of the antioxidant properties of phenols is subject to rigorous scientific scrutiny. Phenolics, especially flavonoids and phenylopropanoids are oxidized by peroxidase and act directly in scavenging molecular species of active oxygen, such as $\mathrm{H}_{2} \mathrm{O}_{2}{ }^{-}$which, if in excess, cause oxidative cellular damage (Vicente and Boscaiu, 2018). These plant-derived compounds are known by reducing the rates of oxidation of organic matter by transferring an $\mathrm{H}$ atom (from their $\mathrm{OH}$ groups) to the chain-carrying ROO* radicals, a mechanism that most likely involves a concerted transfer of the hydrogen as a proton and of one electron between the two oxygen atoms, O-H---O* - protoncoupled electron transfer mechanism (Foti, 2007).

On the basis of our findings, spermine application provides potential for manipulation electrolyte leakage, notably at the higher concentration. According to the results from salt-stressed plants, greater electrolyte leakage was estimated. Results of previous studies yielded consistent and conforming data. For example, Satish et al. (2019) reported that finger millet plants treated with spermidine under water stress showed lower electrolyte leakage, contrary to the findings of untreated control. Measuring the electrolyte leakage from plant tissues, resulting from loss of cell membrane integrity, is commonly used as a function for the extent of tissue damage (Hatsugai and Katagiri, 2018) and to quantify the hypersensitive/programmed cell death, which is considered one of the most powerful and complex defense reactions to survive to pathogen attacks during an incompatible plant-pathogen interaction (Imanifard et al., 2018). Electrolyte leakage typically accompanies plant response to various stresses (Hniličková et al., 2019). It is, therefore, promising to determine the induced damage in leaves due to pathogen attack, insect herbivory, oxidative stress, salinity, drought, frost, heavy metals, hyperthermia, or hypothermia. Accumulating evidence shows that electrolyte leakage is mainly related to $\mathrm{K}+$ efflux from plant cells, which is mediated by plasma membrane cation conductances (Repo and Ryyppo, 2008). These datums support the results obtained and provide irrefutable evidence of the harmful role of salinity and clear explanations of the corrected role of spermine.

\section{Conclusion}

On the basis of the results obtained, spermine was promising in reducing the negative impacts of salinity stress and improving growth/yield of canola. Implication of spermine precisely at $100 \mathrm{ppm}$ resulted in a better efficiency for biochemical characteristics, plant growth and yield productivity and contributed effectively to overcome salinity-induced damages, which are generally associated with an increased risk of plant growth failure. We demonstrate that elevated levels of plant disturbance were alleviated by the abundant production of both enzymatic and non-enzymatic antioxidants or ROS inhibition, providing a supportive indicator and clear knowledge of the role of spermine in the control of the extreme impact of salinity.

\section{Acknowledgements}

This work was supported as part of the research framework scheme of the National Research Centre, Dokki, Cairo Egypt. The authors are grateful to the anonymous reviewers whose constructive comments/suggestions helped clarify and improve this manuscript. 


\section{Abbreviations}

Glutathione reductase, GR; Ascorbate peroxidise, APX: Phenylalanine ammonia lyase, PAL; Glutathione, GSH; Ascorbate, AsA; Reactive oxygen species, ROS; fresh weight, Fr. Wt.; dry weight, Dr. Wt.; electric conductivity (deciSiemens per meter), EC $\left(\mathrm{dSm}^{-1}\right)$; milliequivalents of solute per litre, meq $\mathrm{L}^{-1}$

\section{References}

Abd El-Baky, H.H., A.A. Mohamed and M.M. Hussein, 2003. Influence of salinity on lipid peroxidation, antioxidant enzymes and electrophoretic patterns of protein and isoenzymes in leaves of some onion cultivars. Asian J Plant Sci., 2: 1220-1227. https://scialert.net/abstract/?doi=ajps.2003.1220.1227

Abdallah, M.M.-S., Z.A. Abdelgawad and H.M.S. El-Bassiouny, 2016. Alleviation of the adverse effects of salinity stress using trehalose in two rice varieties. S Afr J Bot., 103: 275-282. https://scialert.net/abstract/?doi=ajcs.2013.405.415

Abdul Qados and A.M.S., 2011. Effect of salt stress on plant growth and metabolism of bean plant Vicia faba (L.). J Saudi Soc Agric Sci., 10(1): 7-15. https://doi.org/10.1016/j.jssas.2010.06.002

Acosta-Motos, J.R., M.F. Ortuño, A. Bernal-Vicente., P. Diaz-Vivancos, Sanchez- M.J. Blanco and J.A. Hernandez, 2017. Plant responses to salt stress: Adaptive mechanisms. Agronomy, 7(18): 138. https://doi.org/10.3390/agronomy7010018

Alcázar, R., T. Altabella, F. Marco, C. Bortolotti, M. Reymond, C. Koncz, et al., 2010. Polyamines: molecules with regulatory functions in plant abiotic stress tolerance. Planta., 231: 1237-1249. https://doi.org/10.1007/s00425-010-1130-0

Ambika, S., V. Manonmani and G. Somasundaram, 2014. Review on effect of seed size on seedling vigour and seed yield. Res J Seed Sci., 7(2): 31-38. https://scialert.net/abstract/?doi=rjss.2014.31.38

Amooaghaie, R. and S. Moghym, 2011. Effect of polyamines on thermotoelrance and membrane stability of soybean seedling. Afr J Biotechnol., 10(4): 9673-9679. http://dx.doi.org/10.5897/AJB10.2446

Arbona, V., V. Flors, J. Jacas, P. García-Agustín and A. Gómez-Cadenas, 2003. Enzymatic and nonenzymatic antioxidant responses of carrizo citrange, a salt-sensitive citrus rootstock, to different levels of salinity. Plant Cell Physiol., 44(4): 388-394. https://doi.org/10.1093/pcp/pcg059

Aroca, R., R. Porcel and J.M. Ruiz-Lozano, 2002. Regulation of root water uptake under abiotic stress conditions. J Exp Bot., 63(1): 43-57. https://doi.org/10.1093/jxb/err266

Aslam, M., K. Ahmad, M.A. Akhtar and M.A. Maqbool, 2017. Salinity stress in crop plants: effects of stress, tolerance mechanisms and breeding strategies for improvement. J Agric Basic Sci., 2(1): $70-85$.

Boem, G.F.H., J.D. Schener and R.S. Lavado, 1994. Some effect of soil salinity on growth development and yield of rapeseed (Brassica napus L.). J Agron Crop Sci., 172: 182-187. https://doi.org/10.1111/j.1439-037X.1994.tb00164.x

Bueno, M. and M.-P. Cordovilla, (2019). Polyamines in halophytes. Front Plant Sci., 5: 151. https://doi.org/10.3389/fpls.2019.00439

Chen, D., Q. Shao, L. Yin, A. Younis and B. Zheng, 2019. Polyamine function in plants: Metabolism, regulation on development, and roles in abiotic stress responses. Front Plant Sci., 9: 1945. https://doi.org/10.3389/fpls.2018.01945

Cheng, N.H., J.K. Pittman, T. Shigaki, J. Lachmansingh, S. LeClere, B. Lahner, et al., 2005. Functional association of Arabidopsis CAX1 and CAX3 is required for normal growth and ion homeostasis. Plant Physiol., 138: 2048-2060. https://doi.org/10.1104/pp.105.061218

Cheng, N.H., J.K. Pittman, J.K. Zhu and K.D. Hirschi, 2004. The protein kinase SOS2 activates the Arabidopsis $\mathrm{H}^{+} / \mathrm{Ca}^{2+}$ antiporter CAX1 to integrate calcium transport and salt tolerance. J Biol Chem., 279: 2922-2926. https://doi.org/10.1074/jbc.M309084200

Das, K. and A. Roychoudhury, 2014. Reactive oxygen species (ROS) and response of antioxidants as ROS-scavengers during environmental stress in plants. Front Environ., $\underline{\text { Sci. }}$ https://doi.org/10.3389/fenvs.2014.00053

Dobrovinskaya, O.R., J. Muñiz and I.I. Pottosin, 1999. Inhibition of vascular ion channels by polyamines. J Membr Biol., 167: 127-140. https://www.ncbi.nlm.nih.gov/pubmed/9916144 
Doke, N., 1983. Involvement of superoxide in the hypersensitive response of potato tuber tissues to infection with an incompatible race of phytophthora infection and to hyphal wall components. Physiol Plant Pathol., 23: 345-357. http://dx.doi.org/10.1016/0048-4059(83)90019-X

Fariduddin, Q., P. Varshney, M. Yusuf and A. Ahmad, 2013. Polyamines: potent modulators of plant responses to stress. J Plant Interact., 8(1): 1-16. https://doi.org/10.1080/17429145.2012.716455

Foti, M.C., 2007. Antioxidant properties of phenols. J Pharm Pharmacol., 59(12): 1673-85. https://doi.org/10.1211/jpp.59.12.0010

Gilley, A. and R.A Fletcher, 1997. Relative efficacy of paclobutrazole, propiconazole and tetranconazole as stress protectants in wheat seedlings. Plant Growth Regul., 21: 169-175. https://doi.org/10.1023/A:1005804717016

Gomez, K.A. and A.A. Gomez, 1984. Statistical Procedures for Agricultural Research. 2 ed. New York: John Wiley \& Sons Inc. $680 \mathrm{p}$.

Gupta, B. and B. Huang, 2014. Mechanism of salinity tolerance in plants: Physiological, biochemical, and molecular characterization. Int J Genomics., 18. http://dx.doi.org/10.1155/2014/701596

Gupta, U.S., 2019. Physiology of Stressed Crops, Vol. 1: Hormone Relations. USA: CRC press. 254 p.

Hasanuzzaman, M., B.M.H.M. Bhuyan,T.I. Anee, K. Parvin, K. Nahar, J. Al Mahmud and M. Fujita, 2019. Regulation of ascorbate-glutathione pathway in mitigating oxidative damage in plants under abiotic stress. Antioxidants, 8(9): 384. https://doi.org/10.3390/antiox8090384

Hatsugai, N. and Katagiri F., 2018. Quantification of plant cell death by electrolyte leakage assay. BioProtoc., 8: 5. http://dx.doi.org/10.21769/BioProtoc.2758

He, C.Y., T. Hsiang and D.J. Wolyn, 2001. Activation of defense responses to Fusarium infection in Asparagus densiflorus. Eur J Plant Path., 107: 473-483. https://doi.org/10.1023/A:1011218304331

$\mathrm{He}, \mathrm{X}$. and S. Gao, 2008. Changes of antioxidant enzyme and phenylalanine ammonia-lyase activities during Chimonanthus praecox seed maturation. Z Naturforsch C. 63(7-8): 569-573. https://doi.org/10.1515/znc-2008-7-818

Hniličková1, H., F. Hnilička1, M. Orsák and V. Hejnák, 2019. Effect of salt stress on growth, electrolyte leakage, $\mathrm{Na}+$ and $\mathrm{K}+$ content in selected plant species. Plant, Soil Environ., 65(2): 90-96. https://doi.org/10.17221/620/2018-PSE

Imanifard, Z., E. Vandelle and D. Bellin, 2018. Measurement of hypersensitive cell death triggered by avirulent bacterial pathogens in arabidopsis. Methods Mol Biol., 1743: 39-50. https://doi.org/10.1007/978-1-4939-7668-34

Isah, T., 2019. Stress and defense responses in plant secondary metabolites production. Biol Res., 52: 39. https://doi.org/10.1186/s40659-019-0246-3

Isayenkov, S.V. and F.J.M. Maathuis, 2019. Plant salinity stress: Many unanswered questions remain. Front Plant Sci., 10: 80. https://doi.org/10.3389/fpls.2019.00080

Jamil, A., S. Riaz, M. Ashraf and M.R. Foolad., 2011. Gene expression profiling of plants under salt stress. Crit Rev Plant Sci., 30(5): 435-458. https://doi.org/10.1080/07352689.2011.605739

Jana, S. and M.A. Choudhuri, 1981. Glycolate metabolism of the three submerged aquatic angiosperm during aging. Aquat Bot., 12: 345-352. http://dx.doi.org/10.1016/0304-3770(82)90026-2

Josephson, A.L., J. Ricker-Gilbert and R.J. Florax, 2014. How does population density influence agricultural intensification and productivity? Evidence from Ethiopia. Food Policy, 48(c): 142152. http://dx.doi.org/10.1016/j.foodpol.2014.03.004

Karmakar, R., I. Das, D. Dutta and A. Rakshit, 2016. Potential effects of climate change on soil properties. Sci Int., 4(2): 51-73. https://scialert.net/abstract/?doi=sciintl.2016.51.73

Katerji, N., J.W. van Hoorn, A. Hamdy, F. Karam and M. Mastrorilli, 1996. Effect of salinity on water stress, growth, and yield of maize and sunflower. Agric Water Manag. 30(3): 237-249. https://doi.org/10.1016/0378-3774(95)01228-1

Kelley, P.M. and S. Izawa, 1978. The role of chloride ion in photosystem II. I. Effects of chloride ion on photosystem II electron transport and on hydroxylamine inhibition. Biochim Biophys Acta., 502(2): 198-210. https://doi.org/10.1016/0005-2728(78)90042-7

Kiran, B.R., 2019. Defense manifestations of enzymatic and non-enzymatic antioxidants in Ricinus communis L. exposed to lead in hydroponics. EBTJ, 3: (3). https://doi.org/10.2478/ebtj-2019$\underline{0014}$ 
Krasensky, J. and C. Jonak, 2012. Drought, salt, and temperature stress-induced metabolic rearrangements and regulatory networks. J Exp Bot., 63(4): 1593-1608. https://doi.org/10.1093/jxb/err460

Kusano, T., K. Yamaguchi, T. Berberich and Y. Takahashi, 2007. The polyamine spermine rescues arabidopsis from salinity and drought stresses. Plant Signal Behav. 2(4): 251-252. https://doi.org/10.4161/psb.2.4.3866

Liu, J.-G., W. Wang, H. Wu, X. Gong and T. Moriguchi, 2015a. Polyamines function in stress tolerance: from synthesis to regulation. Front Plant Sci., 6: 827. https://doi.org/10.3389/fpls.2015.00827

Liu, M., M. Chu, Y. Ding, S. Wang, Z. Liu, S. Tang, et al., 2015b. Exogenous spermidine alleviates oxidative damage and reduce yield loss in rice submerged at tillering stage. Front Plant Sci., 6: 919. https://doi.org/10.3389/fpls.2015.00919

Liu, Y., D. Gu, W. Wu, X. Wen and Y. Liao, 2013. The relationship between polyamines and hormones in the regulation of wheat grain filling. PLoS ONE., 8(10): e78196. https://doi.org/10.1371/journal.pone.0078196

Lobell, D.B., K.G. Cassman and C.B. Field, 2009. Crop yield gaps: their importance, magnitudes, and $\begin{array}{lllll}\text { causes. Ann Rev } & \text { Environ }\end{array}$ https://doi.org/10.1146/annurev.environ.041008.093740

Marschner, H., 1995. Mineral Nutrition of Higher Plants. 2 ed. London: Academic Press. 889 p.

Mousavi, S., L. Regni, M. Bocchini, R. Mariotti, N.G.M. Cultrera, S. Mancuso et al., 2019. Physiological, epigenetic and genetic regulation in some olive cultivars under salt stress. Sci Rep., 9: 1093. https://doi.org/10.1038/s41598-018-37496-5

Nahar, K., M. Hasanuzzaman, A. Rahman, M.D.M. Alam, J. Al Mahmud, T. Suzuki, et al., 2016. Polyamines confer salt tolerance in mung bean (Vigna radiata L.) by reducing sodium uptake, improving nutrient homeostasis, antioxidant defense, and methylglyoxal detoxification systems. Front Plant Sci., 7: 1104. https://doi.org/10.3389/fpls.2016.01104

Nakano, Y. and K. Asda, 1981. Hydrogen peroxide is scavenged by ascorbate specific peroxidise in spinach chloroplasts. Plant Cell Physiol., 22: 867-880. https://doi.org/10.4236/ajac.2014.511081

Negrão, S., S.M. Schmöckel and M. Tester, 2017. Evaluating physiological responses of plants to salinity stress. Ann Bot., 119(1): 1-11. https://doi.org/10.1093/aob/mcw191

Orabi, S.A. and M.S. Sadak, 2015. Improvement of productivity and quality of two wheat cultivars by foliar application of spermine and paclobutrazol. Middle East J Agric Res., 4(2): 195-203.

Patel, P.R., S.S. Kajal, V.R. Patel, V.J. Patel and S.M. Khristi, 2010. Impact of salt stress on nutrient uptake and growth of cowpea. Braz J Plant Physiol., 22(1): 43-48. http://dx.doi.org/10.1590/S1677-04202010000100005

Paul, S., A. Banerjee and A. Roychoudhury, 2018. Role of polyamines in mediating antioxidant defense and epigenetic regulation in plants exposed to heavy metal toxicity. In: Hasanuzzaman M., Nahar K., Fujita M., Eds., Plants Under Metal and Metalloid Stress. Singapore: Springer. p. 229-247.

Racchi, M.L., 2013 Antioxidant defenses in plants with attention to Prunus and Citrus spp. Antioxidants (Basel), 2(4): 340-369. https://doi.org/10.3390/antiox2040340

Reda, M., M. Migocka and G. Klobus, 2011. Effect of short-term salinity on the nitrate reductase activity in cucumber roots. Plant Sci., 180(6): 783-788. https://doi.org/10.1016/j.plantsci.2011.02.006

Repo, T. and A. Ryyppo, 2008. The electrolyte leakage method can be misleading for assessing the frost hardiness of roots. Plant Biosyst. 142(2): 298-301. https://doi.org/10.1080/11263500802150548

Rezaei1, Y., A. Tavakoli1, F. Shekari, J. Nikbakht, K. Juhos and M. Ansari, 2017. Effect of salinity stress on biochemical and physiological aspects of Brassica napus L. cultivars. Acad J Agric Res. 5(5): 110-116. https://doi.org/10.15413/ajar.2017.0116

Rezayian, M.V.N. and H. Ebrahimzadeh, 2018. Differential responses of phenolic compounds of Brassica napus under drought stress. Iran J Plant Physiol., 8(3): 2417-2425.

Rezazadeh, A., A. Ghasemnezhad, M. Barani and T. Telmadarrehei, 2012. Effect of salinity on phenolic composition and antioxidant activity of artichoke (Cynara scolymus L.) leaves. Res J Med Plants., 6: 245-252. https://scialert.net/abstract/?doi=rjmp.2012.245.252 
Roychoudhury, A., S. Basu and D.N. Sengupta, 2011, Amelioration of salinity stress by exogenously applied spermidine or spermine in three varieties of indica rice differing in their level of salt tolerance. J Plant Physiol., 168(4): 317-328. https://doi.org/10.1016/j.jplph.2010.07.009

Saha, J., E.K. Brauer, A. Sengupta, S.C. Popescu, K. Gupta and B. Gupta, 2015. Polyamines as redox homeostasis regulators during salt stress in plants. Front Environ Sci., 3: 21. https://doi.org/10.3389/fenvs.2015.00021

Saleethong, P., J. Sanitchon, K.K. Ngern and P. Theerakulpisu, 2013. Effects of exogenous spermidine (Spd) on yield, yield-related parameters and mineral composition of rice (Oryza sativa L. ssp. indica) grains under salt stress. Aust J Crop Sci., (9): 1293-1301.

Saleethong, P., J. Sanitchon, K. Kong-ngern and P. Theerakulpisut, 2011. Pretreatment with spermidine reverses inhibitory effects of salt stress in two rice (Oryza sativa L.) cultivars differing in salinity tolerance. Asian Plant Sci., 10(4): 245-254. https://scialert.net/abstract/?doi=ajps.2011.245.254

Satish, L., A.S. Rency and M. Ramesh, 2018. Spermidine sprays alleviate the water deficit-induced oxidative stress in finger millet (Eleusine coracana L. Gaertn.) plants. 3 Biotech., 8(1): 63. https://doi.org/10.1007/s13205-018-1097-2

Scheumann, W. and C. Freisem, 2002. The role of drainage for sustainable agriculture. J Appl Irrigat Sci., 37(1): 33-61.

Seifi, H.S. and B.J. Shelp, 2019. Spermine differentially refines plant defense responses against biotic and abiotic stresses. Front Plant Sci., 10: 117. https://doi.org/10.3389/fpls.2019.00117

Seifi, H.S., A. Zarei, T. Hsiang and B.J. Shelp, 2019. Spermine is a potent plant defense activator against gray mold disease on Solanum lycopersicum, Phaseolus vulgaris, and Arabidopsis thaliana. Phytopathology, 109(8): 1367-1377. https://doi.org/10.1094/PHYTO-12-18-0470-R.

Sharma, P., A.B. Jha, R.S. Dubey and M. Pessarakli, 2012. Reactive oxygen species, oxidative damage, and antioxidative defense mechanism in plants under stressful conditions. J Bot., 2012: 26. https://doi.org/10.1155/2012/217037

Sheldon, A., N.W. Menzies, H.P. So and R. Dalal, 2004. The effect of salinity on plant available water. SuperSoil 2004: 3rd Australian New Zealand Soils Conference, 5-9 December 2004, University of Sydney, Australia. Published on CDROM. https://www.regional.org.au/au/asssi/ (Accessed: 5 March 2019)

Silber, R., M. Farber, E. Papopoulos, D. Nervla, L. Liebes, M. Bruch, et al., 1992. Glutathione depletion in chronic lymphocytic leukemia B-lymphocytes. Blood, 80: 2038-2040. https://www.ncbi.nlm.nih.gov/pubmed/1356514

Takahashi, Y., T. Berberich, A. Miyazaki, S. Seo, Y. Ohashi and T. Kusano, 2003. Spermine signalling in tobacco: activation of mitogen-activated protein kinases by spermine is mediated through mitochondrial dysfunction. Plant J., 36: 820-829. https://doi.org/10.1046/j.1365313X.2003.01923.X

Todorova, D., Z. Katerova, I. Sergiev and V. Alexieva, 2013. Role of polyamines in alleviating salt stress. In: Ahmad et al., Eds., Soil and Water Management For Sustained Agriculture in Alluvial Plains and Flood Plains Exposed to Salinity: A Case Of Neretva River Valley. $1^{\text {st }}$ Edn. New York: Springer. p. 355-379. https://doi.org/10.1007/978-1-4614-4747-4_13

Vicente, O. and M. Boscaiu, 2018. Flavonoids: antioxidant compounds for plant defence and for a healthy human diet. Not Bot Horti Agrobo., 46(1): 14-21. https://doi.org/10.15835/nbha46110992

Volkmar, K.M., Y. Hu and H. Steppuhn, 1998. Physiological responses of plants to salinity. Can J Plant Sci., 78(1): 19-27. https://doi.org/10.4141/P97-020

Walia, H., C. Wilson, P. Condamine, X. Liu, A.M. Ismail, L. Zeng, et al., 2005. Comparative transcriptional profiling of two contrasting rice genotypes under salinity stress during the vegetative growth stage. Plant Physiol., 139: 822-835. https://doi.org/10.1104/pp.105.065961

Xie, X., Z. He, N. Chen, Z. Tang, Q. Wang, and Y. Cai, 2019. The roles of environmental factors in regulation of oxidative stress in plant. Biomed Res Int., 2019: 9732325. https://doi.org/10.1155/2019/9732325

Yang, J., J. Zhang, K. Liu, Z. Wang, and L. Liu, 2007. Involvement of polyamines in the drought resistance of rice. J Exp Bot., 58(6): 1545-1555. https://doi.org/10.1093/jxb/erm032 
Zaghdoudi, M., N. Msilini, S. Govindachary and M. Lachaâl, 2011. Inhibition of photosystems I and II activities in salt stress-exposed Fenugreek (Trigonella foenum graecum). J Photochem Photobiol., 105(1): 14-20. https://doi.org/10.1016/j.jphotobiol.2011.06.005

Zanetti, G., 1979. Rabbit liver glutathione reductase, purification and properties. Arch Biochem Physiol. 198: 241-246. https://doi.org/10.1016/0003-9861(79)90415-6

Zhang, W., and S.Y. Wang, 2001. Antioxidant activity and phenolic compounds in selected herbs. J Agric Food Chem., 49: 5165-5170. www.ncbi.nlm.nih.gov/pubmed/11714298

Zhu, J.K., 2001. Plant salt tolerance. Trends Plant Sci., 6: 66-71. https://doi.org/10.1016/S1360$\underline{1385(00) 01838-0}$ 